\title{
Study of the Influence of Sheet Pile Location under Dams on Groundwater Flow and Pore Pressure with Network Method
}

\author{
Encarnación Martínez-Moreno ${ }^{1}$, Gonzalo García-Ros ${ }^{1}$, Iván Alhama ${ }^{1}$ \\ ${ }^{1}$ Civil Engineering Department, Technical University of Cartagena \\ Paseo Alfonso XIII 52, Cartagena, Spain \\ encarni.martinez@upct.es; gonzalo.garcia@upct.es; ivan.alhama@upct.es
}

\begin{abstract}
The construction of a gravity dam leads to some verifications that may affect its safety, such as groundwater flow or pore pressure distribution under the structure. These phenomena, which are related to piping and the position of the uplift force, can be controlled by placing a sheet pile under the dam. The variables are commonly studied as if the soil was isotropic, simplifying universal results (either graphics or formulations). However, this assumption does not reflect real scenarios in most of the cases, for example anisotropic hydraulic conductivities. In this work, the effects of the sheet pile position in four different cases is studied: dam without a sheet pile and dam with a sheet pile located at the heel, centre and toe of the structure. In all of them two different media are modelled, with isotropic and anisotropic hydraulic conductivities, so its influence can be appraised from the point of view of safety. The scenarios are simulated with a tool based on the network method that, employing the electrical analogy, obtains the problem variables, 'hydraulic potential' (h) and 'water flow' (Q), solving electric quantities, 'voltage' (V) and 'electric current' (I), respectively.
\end{abstract}

Keywords: dam safety, network method, sheet piles, electrical analogy.

\section{Introduction}

Controlling groundwater flow is a common objective in geotechnics and ground engineering. In order to achieve it, retaining structures are built in water courses, such as rivers, or in excavations affected by phreatic level. Examples of these retaining structures are concrete, earth or coffer dams, depending on the period of time that they are designed to work or the material they are made of.

Focusing on concrete dams built as permanent structures, the variables that are usually studied are water flow through the porous medium from the upstream side to the downstream side and pore pressure distribution generated under the structure due to this flow. The last phenomenon can be studied in a simpler way as the uplift force and its application point. The two phenomena are related to dam safety [1]: on the one hand, large groundwater flow rates may be a risk at the structure toe; on the other hand, pore pressure plays a role in safety calculations of overturning and sliding [2].

In order to control these phenomena, sometimes it is convenient to place one or several sheet piles under the dam. If employing them, flow rate is reduced, and values of uplift forces and application point are altered according to the position and number of sheet piles that have been built [3]. For some configurations, analytical solutions have been developed, and they can be found in different reference manuals $[4,5]$, although only considering isotropic soil. Therefore, these results are relatively reliable, since most soils are anisotropic, with larger values of hydraulic conductivity in the horizontal direction.

Another possible way to study the variables are flow nets, since the values of groundwater flow and pore pressure distribution under the structure can be calculated from stream lines and iso-potential lines. The rules to draw flow nets, which can be found in geotechnical manuals, are based on the assumption of isotropic medium. However, mathematical manipulations are presented to allow the application of the methodology in anisotropic soils.

Finally, numerical methods on which software are based can quantify these phenomena in isotropic and anisotropic soils. Among all the possible options, the tool that has been employed in this paper is the network method, which has already been applied in the study of different physical problems, such as flow in porous media [6], soil consolidation [7], and solute and heat transport $[8,9]$. The method employs the electrical analogy of the problem variables, so the hydraulic potential, $h$, is equivalent to the voltage, $\mathrm{V}$, and the groundwater flow, $\mathrm{Q}$, to the electric current or intensity, I. This is a reliable equivalence because the governing equations in both problems are similar. 
In this way, each cell obtained by the discretization of the geometry is transformed into an electric circuit with four resistors, whose resistance value depends on the hydraulic conductivity in the considered direction and the volume element size. Once all the circuits have been built, they are introduced in Ngspice [10], a free software developed for solving electric circuits. The values obtained from Ngspice are voltage and intensity for all the cells, and from them, the sought solutions can be calculated.

In this paper, the values of groundwater flow, uplift force and application point are presented for scenarios of dam with a sheet pile located in different positions (dam heel, middle and toe) and without a sheet pile, for two different soils (isotropic and anisotropic). Thus, the effects of the sheet pile and the anisotropy can be studied.

\section{Studied Problem}

Throughout this paper, the geometry that is employed for comparing results is that presented in Figure 1, in which the nomenclature of the problem is also shown. It is a dam without a foundation on a zone of large horizontal length. Upstream and downstream the dam there is a hydraulic potential change that generates the flow.

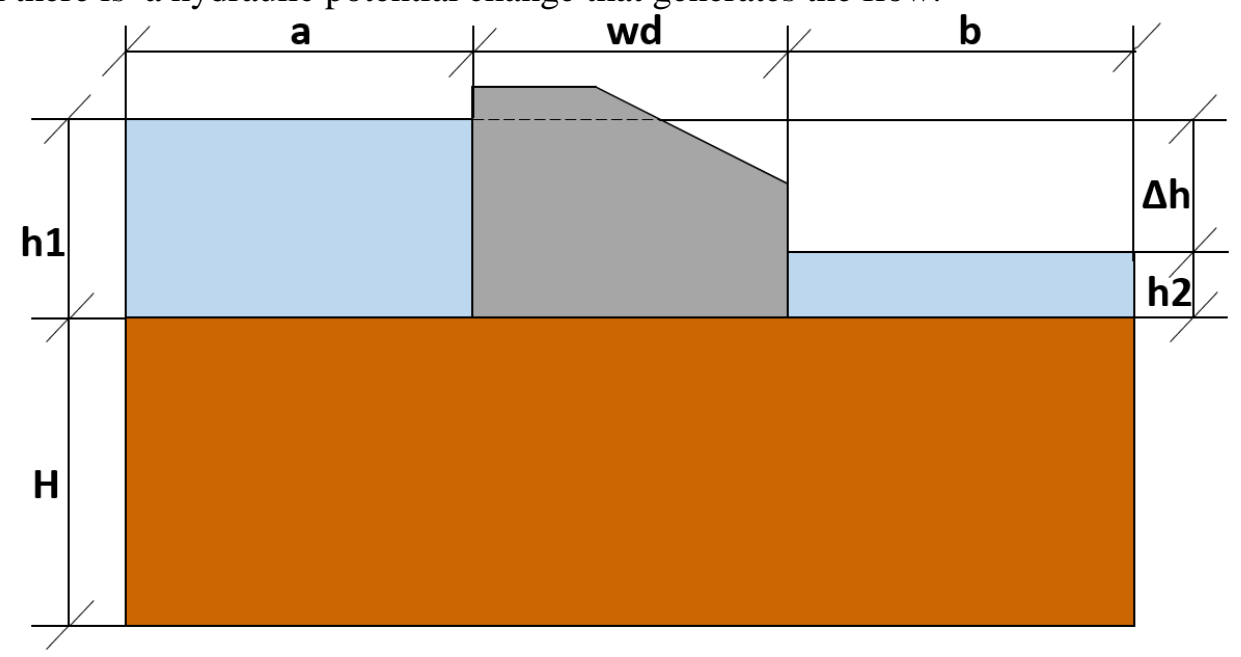

Fig. 1: Scheme and nomenclature of the problem

According to Figure 1, the dimensions are:

- $\quad$ a: upstream length, in meters, 50.

- $\quad \mathrm{w}_{\mathrm{d}}$ : dam width, in meters, 10.

- $\quad$ b: downstream length, in meters, 50.

- $\quad$ h1: upstream hydraulic potential, in meters, 10.

- $\quad$ h2: downstream hydraulic potential, in meters, 0 .

- $\quad \Delta \mathrm{h}$ : hydraulic potential change, in meters, 10.

- $\quad$ H: stratum thickness, in meters, 20.

In addition, in scenarios with a sheet pile, this has a length, $d_{s}$, of 5 meters, while its thickness is negligible for this cases. Anyway, when running the code, it must be given a value (10 $\mathrm{cm}$ in these simulations).

In those cases in which the scenario is isotropic, both conductivities, $\mathrm{k}_{\mathrm{x}}$ and $\mathrm{k}_{\mathrm{y}}$, have a value of $10^{-5} \mathrm{~m} / \mathrm{s}$, which means that it is a clay sand. For anisotropic scenarios, $\mathrm{k}_{\mathrm{x}}$ keeps the same value, but $\mathrm{k}_{\mathrm{y}}$ is reduced to $10^{-6} \mathrm{~m} / \mathrm{s}$.

\section{Solutions Based on the Network Method}

\subsection{Electrical Analogy}

Discretizing the geometry of the problem in cells is the first step to employ this methodology. For this reason, it is necessary to consider a sheet pile thickness since at least a column of cells is used to simulate it. Each of the cells is transformed into a part of the general circuit with two resistors in each direction. Their resistance value depends on the cell size and the hydraulic conductivity in the studied direction. 
Once all the data are transformed to create the electrical circuit, it is introduced in Ngspice for solving it. In this way, value of voltage (hydraulic potential) in nodes and electric current (water flow) in branches are obtained. Using these values, the solutions of the problems are built. There are two kinds of results:

- Graphical solutions. An example can be the flow nets provided by the tool, which allow understanding the behaviour of the flow under the dam and they are different if the soil is isotropic or anisotropic, as well as change according to the position of the sheet pile under the dam. Examples of these solutions are Figures 2 and 3, which show the flow net when the sheet pile is located at the dam toe for the isotropic and the anisotropic scenarios, respectively. Moreover, other graphical results can be obtained, such as the pore pressure distribution under the dam. Figure 4 is a summary of the distributions for all the configurations presented in this document.

- Numerical solutions. They are obtained by mathematical calculations in which the input information are the Ngspice results for all the cells. Therefore, the tool provides values of groundwater flow, uplift force and application point, which is the information presented in this paper. In addition, more variables can be calculated, such as exit gradient or characteristic lengths (zones through which most of the flow occurs)

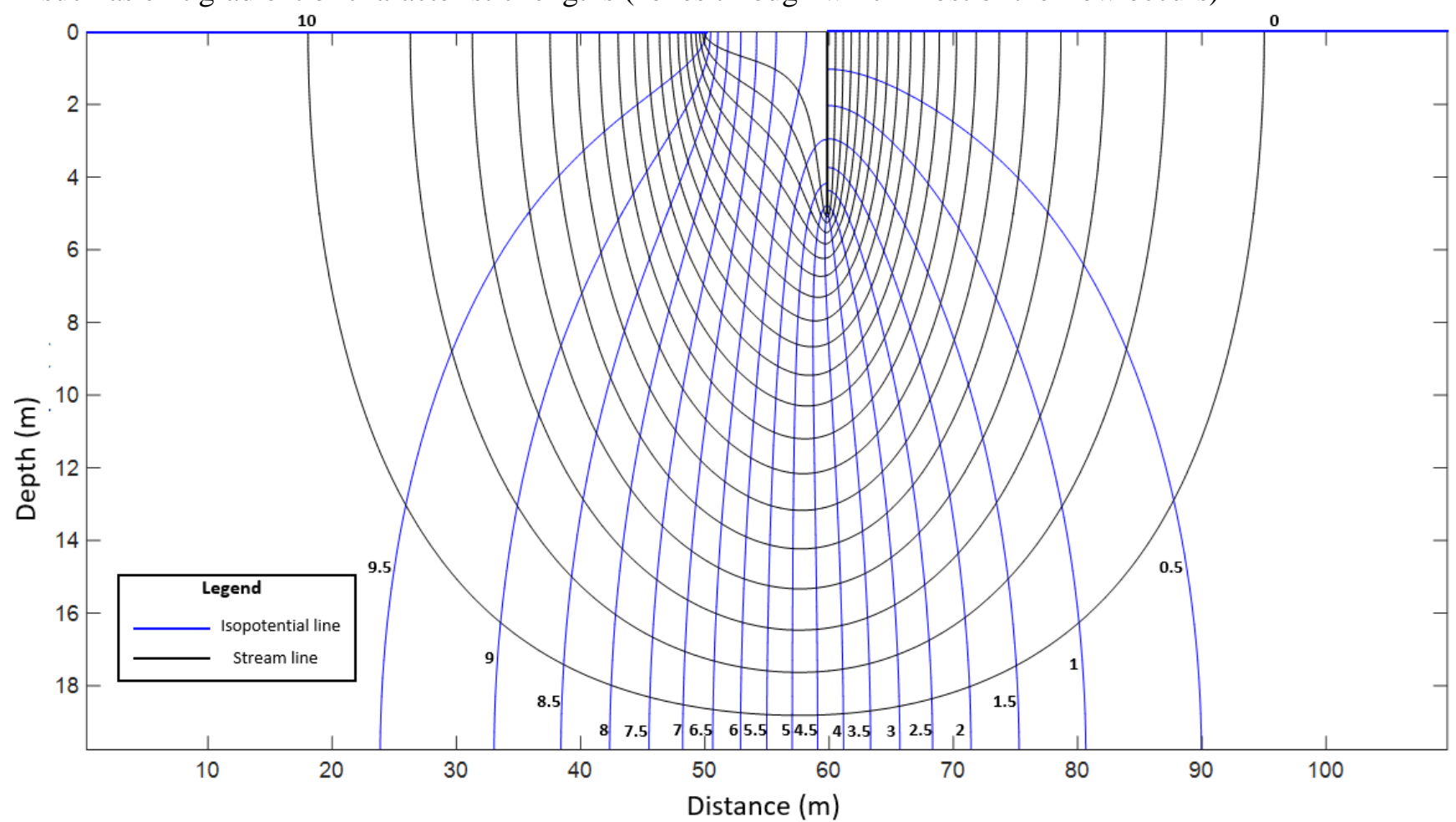

Fig. 2: Flow net of dam with a sheet pile at the toe in isotropic soil 


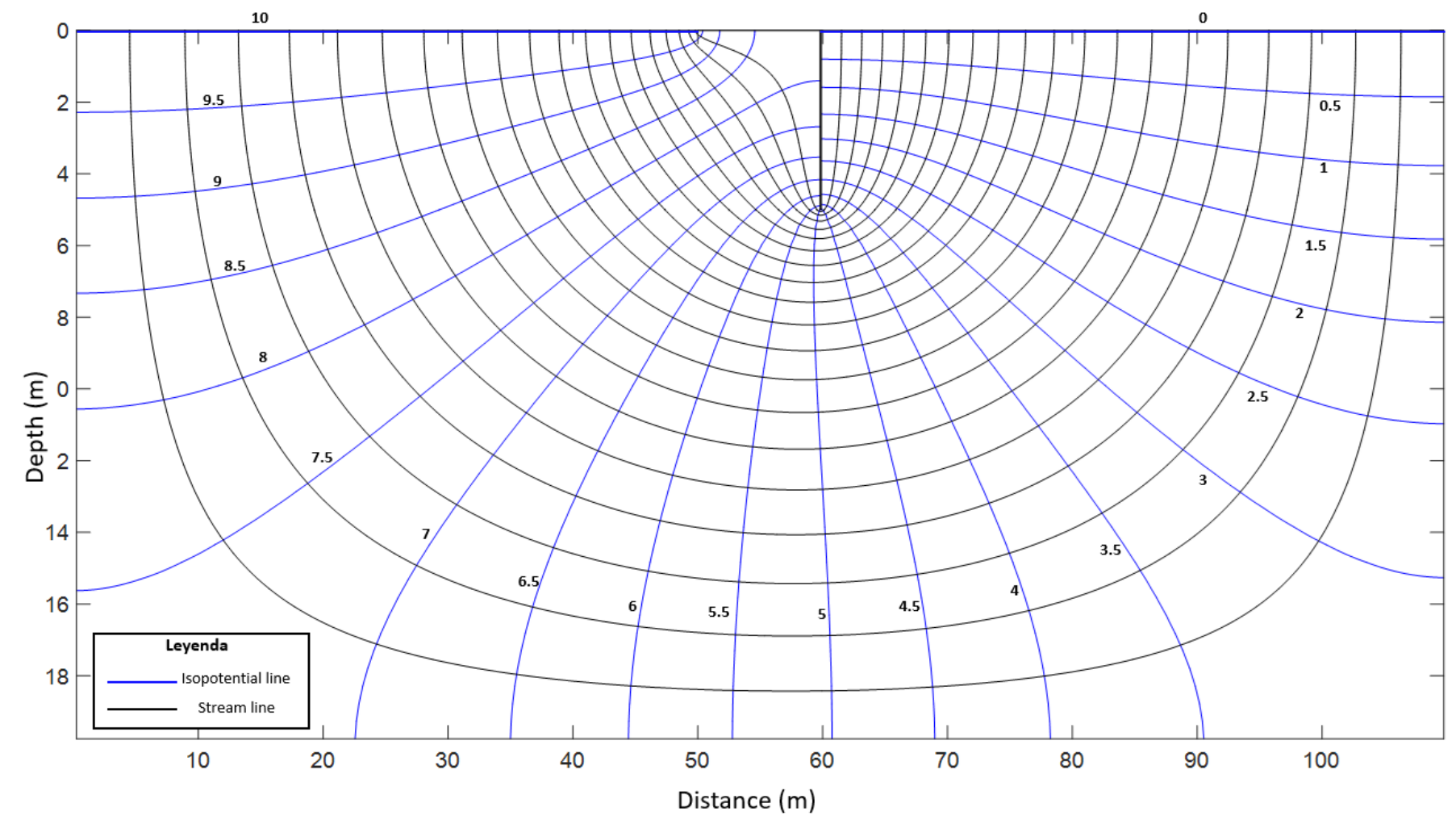

Fig. 3: Flow net of dam with a sheet pile at the toe in anisotropic soil

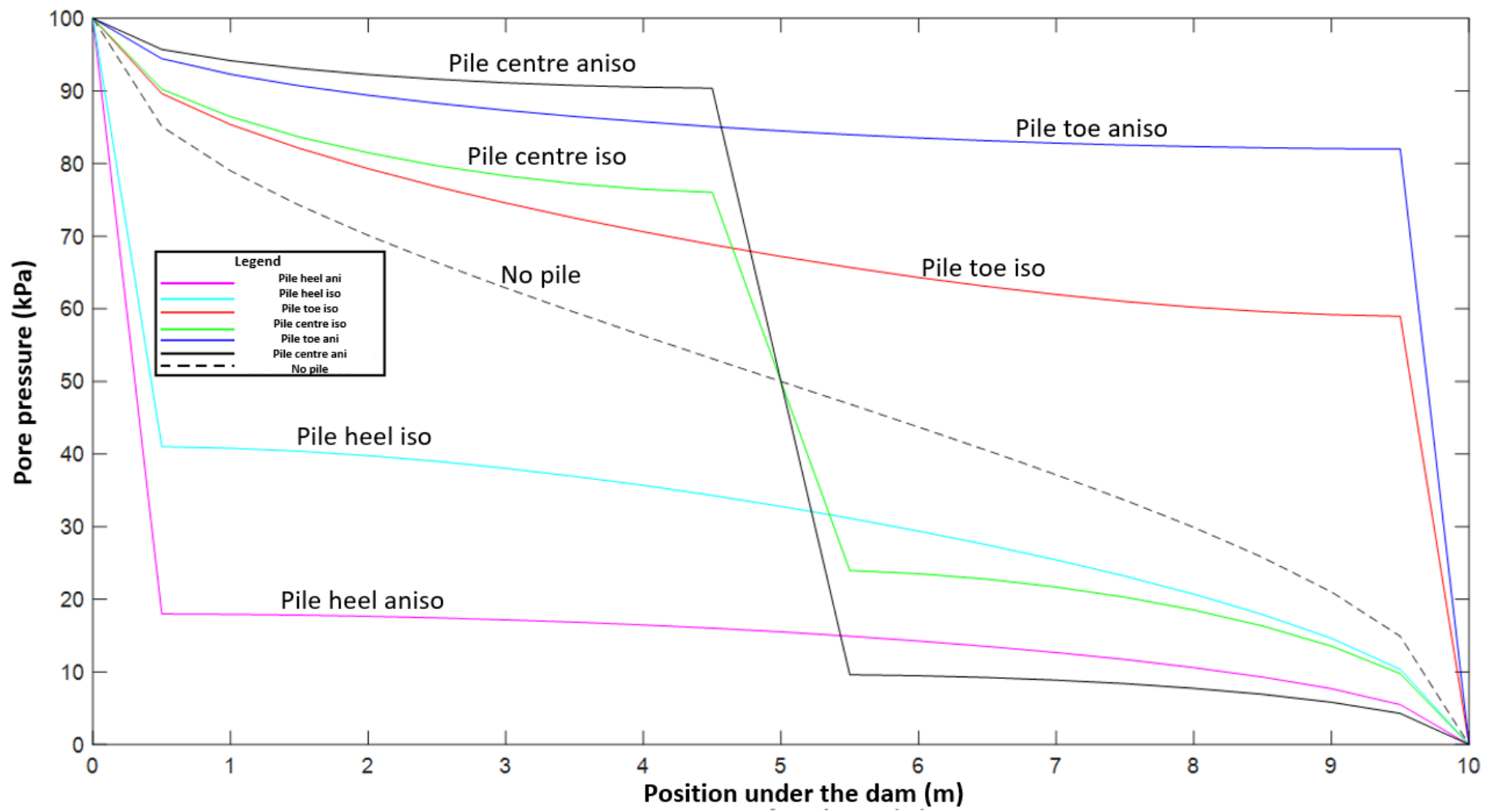

Fig. 4: Pore pressure distribution of all the configurations 


\subsection{Results and comparisons}

The cases that have been chosen for this study allow comparing their results. Thus, the same geometry is applied to isotropic and anisotropic scenarios, the effect of the anisotropy degree, A.D. -Eq (1)- or the equivalent hydraulic conductivity, $k-\mathrm{Eq}(2)-$ can be observed. These are useful parameters when two or more scenarios with different conductivities are studied. Moreover, the combination of both allows quantifying the global permeability of the soil and how the horizontal and the vertical conductivities are related.

$$
\begin{gathered}
\text { A.D. }=\frac{k_{x}}{k_{y}} \\
k=\sqrt{k_{x} \cdot k_{y}}
\end{gathered}
$$

In this way, for the isotropic cases, the anisotropy degree has a value of $A . D .=1$ and an equivalent conductivity of $k=10^{-}$ ${ }^{5} \mathrm{~m} / \mathrm{s}$ is taken, while the anisotropic examples have an $A . D .=10$ and a $k=3.1610^{-6} \mathrm{~m} / \mathrm{s}$. It is visible, then, that the anisotropic soil is less permeable than the isotropic case.

Moreover, between the cases with and without sheet pile, since the only difference is its existence and location, results can also be compared. In order to simplify the comprehension of groundwater flow, uplift force and application point results, cases are presented according to the nomenclature in Table 1. This table also shows the results for each of the studied variables, where $\mathrm{Q}$ is the groundwater flow, $\mathrm{F}$ is the uplift force and $\mathrm{C}$ is the application point.

Table 1: Nomenclature and variable values for all cases.

\begin{tabular}{|l|l|l|l|l|}
\hline Name & Description & $Q\left(\mathrm{~m}^{3} / \mathrm{s} / \mathrm{m}\right)$ & $F(\mathrm{kN} / \mathrm{m})$ & $C(\mathrm{~m})$ \\
\hline I.N.S & Dam in isotropic medium without a sheet pile & $7.40 \cdot 10^{-5}$ & 500.10 & 3.73 \\
\hline A.N.S & Dam in anisotropic medium without a sheet pile & $3.23 \cdot 10^{-5}$ & 500.10 & 3.75 \\
\hline I.S.H & Dam in isotropic medium with a sheet pile at the heel & $5.85 \cdot 10^{-5}$ & 314.65 & 3.88 \\
\hline A.S.H & Dam in anisotropic medium with a sheet pile at the heel & $1.99 \cdot 10^{-5}$ & 160.64 & 3.69 \\
\hline I.S.C & Dam in isotropic medium with a sheet pile at the centre & $6.23 \cdot 10^{-5}$ & 500.03 & 3.26 \\
\hline A.S.C & Dam in anisotropic medium with a sheet pile at the centre & $2.03 \cdot 10^{-5}$ & 500.03 & 2.82 \\
\hline I.S.T & Dam in isotropic medium with a sheet pile at the toe & $5.85 \cdot 10^{-5}$ & 685.34 & 4.49 \\
\hline A.S.T & Dam in anisotropic medium with a sheet pile at the toe & $1.99 \cdot 10^{-5}$ & 839.41 & 4.75 \\
\hline
\end{tabular}

According to Table 1, some interesting results can be pointed out:

- The position in which the sheet pile is located must be thoroughly studied, since it can increase or decrease the uplift force (in isotropic scenarios the maximum difference is $370.69 \mathrm{kN} / \mathrm{m}$, while for anisotropic scenarios this grows up to $678.77 \mathrm{kN} / \mathrm{m}$ ). If other factors must be considered when deciding its location, a compromise solution must be chosen in order to guarantee the safety of the structure from all the points of view considered in the project.

- Anisotropy must be studied employing both variables, anisotropy degree, $A . D$., and equivalent conductivity, $k$, not only one of them, since depending on the variable on which we are focussing, one or the other parameter becomes important.

Results can be compared in different ways. The effects of A.D. and k can be studied, as well as the effect of placing a sheet pile on the behaviour of the variables of interest. Finally, we can understand how the location of the sheet pile under the dam affects the problem.

\subsubsection{Comparison According To Anisotropy}

In line with the results obtained from the simulations, the following percentages are obtained employing Eq. (3):

$$
\% \text { Value }_{I S O-A N I S O}=\frac{\text { Value }_{I S O}-\text { Value }_{\text {ANISO }}}{\text { Value }_{I S O}} 100 \%
$$

In Eq. (3) \%ValueISO-ANISO is the value of the comparison between isotropic and anisotropic results of the studied variables, Value ISo is the isotropic value of the variable, and Value ${ }_{A N I S O}$ is the value of the variable in the anisotropic scenario.

Groundwater flow variable leads to the following results:

- $\quad \% Q_{\text {I.N.S-A.N.S }}=56.08 \%$. 
- $\quad \% Q_{I S . H-A S . H}=65.98 \%$.

- $\quad \% Q_{\text {I.S.C-A.S.C }}=67.42 \%$.

- $\quad \% Q_{\text {I.S.T-A.S.T }}=65.98 \%$.

For the uplift force, the comparisons are:

- $\quad \% F_{I . N . S-A . N . S}=0 \%$.

- $\quad \% F_{I . S . H-A . S . H}=48.95 \%$.

- $\% F_{\text {I.S.C-A.S.C }}=0 \%$.

- $\quad \% F_{\text {I.S.T-A.S.T }}=-22.48 \%$.

Finally, for the application point:

- $\% C_{\text {I.N.S-A.N.S }}=-0.54 \%$.

- $\quad \% C_{\text {I.S.H-A.S.H }}=5.93 \%$.

- $\quad \% C_{\text {I.S.C-A.S.C }}=13.50 \%$.

- $\quad \% C_{\text {I.S.T-A.S.T }}=-5.79 \%$.

If the comparisons of groundwater flow are studied, it is observed that the variable decreases in anisotropic scenarios due to their lower equivalent conductivity, $k$.

Focusing on the comparison of uplift force, the variable is not altered because of anisotropy in scenarios without sheet pile or with a sheet pile at the centre of the dam base. However, the uplift force decreases as the anisotropy degree increases if the sheet pile is located at the dam heel, and the opposite occurs if it is at the dam toe.

Finally, the application point is hardly affected by the anisotropy degree for the scenarios of dam without a sheet pile. Nevertheless, increasing the anisotropy degree, the value of the application point decreases when the sheet pile is located at the dam toe and centre of the dam base, and it is increased if located at the dam heel.

\subsubsection{Comparison Between Dam With A Sheet Pile And Dam Without A Sheet Pile}

In this case, the values compared are those of the scenario without a sheet pile and those with sheet pile in each location. In the same way, results for isotropic and anisotropic configurations are separately presented. The comparison is calculated as shown in Eq. (4):

$$
\% \text { Value }_{N O-W I T H}=\frac{\text { Value }_{N O}-\text { Value }_{\text {WITH }}}{\text { Value }_{N O}} 100 \%
$$

In Eq. (4), \%ValueNO-WITH is the result of the comparison of the studied variable between the value in the scenario without a sheet pile and that of dam with a sheet pile (different percentages for each positionH, $\mathrm{C}$, or $\mathrm{T}$ of the pile under the dam), ValueNO is the value of the variable for the scenario without a sheet pile, and ValueWITH is the value of the variable if a sheet pile is under the dam.

Groundwater flow, for the isotropic cases, leads to the following results:

- $\% Q_{\text {I.N.S-I.S.H }}=20.95 \%$.

- $\% Q_{\text {I.N.S-I.S.C }}=15.81 \%$.

- $\% Q_{\text {I.N.S-I.S.T }}=20.95 \%$.

While for anisotropic, results are:

- $\% Q_{\text {A.N.S-A.S.H }}=38.39 \%$.

- $\% Q_{\text {A.N.S-A.S.C }}=37.15 \%$.

- $\quad \% Q_{\text {A.N.S-A.S.T }}=38.39 \%$.

For the case of uplift force in isotropic scenarios, the percentages are:

- $\% F_{I . N . S-I . S . H}=37.08 \%$.

- $\quad \% F_{I . N . S-I . S . C}=0.01 \%$.

- $\quad \% F_{\text {I.N.S-I.S.T }}=-37.04 \%$.

Whereas, uplift force, for anisotropic cases, leads to:

- $\quad \% F_{\text {A.N.S-A.S.H }}=67.88 \%$.

- $\quad \% F_{\text {A.N.S }- \text { A.S.C }}=0.01 \%$.

- $\quad \% F_{\text {A.N.S-A.S.T }}=-67.85 \%$.

The application point of the uplift force for isotropic scenarios brings the following percentages:

- $\% C_{\text {I.N.S-I.S.H }}=-4.02 \%$. 
- $\quad \% C_{I . N . S-I . S . C}=12.60 \%$.

- $\quad \% C_{\text {I.N.S-I.S.T }}=-20.83 \%$.

For scenarios with anisotropic soil, the comparisons between the application point values are:

- $\quad \% C_{\text {A.N.S }-A . S . U}=1.60 \%$.

- $\quad \% C_{\text {A.N.S-A.S.C }}=24.80 \%$.

- $\quad \% C_{\text {A.N.S }- \text { A.S.D }}=-26.67 \%$.

We observe that groundwater flow variable is reduced when placing a sheet pile, either for isotropic or anisotropic scenarios. The reduction increases with the anisotropy degree.

The uplift force value is the same whether there is a sheet pile at the dam centre or without a sheet pile. It occurs in isotropic and anisotropic scenarios. If the sheet pile is located at the dam heel, the force is reduced if compared to that without a sheet pile, and the opposite happens with the sheet pile at the dam toe.

Finally, the application point of the uplift force is not very affected when placing the sheet pile at the dam heel, independently of the anisotropy degree. If it is placed at the centre of the dam base, the value is reduced, and the reduction is more important as the A.D. increases; and it is increased if the sheet pile is located at the dam toe.

\subsubsection{Comparison according to the location of the sheet pile}

In order to carry out these comparisons, the base values are those of the sheet pile located at the centre of the dam base. Eq. (5) is employed for calculating these percentages.

$$
\% \text { Value }_{C E N T-E X T}=\frac{\text { Value }_{C E N T}-\text { Value }_{\text {EXT }}}{\text { Value }_{C E N T}} 100 \%
$$

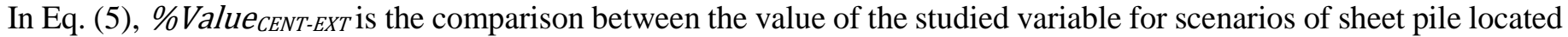
at the centre of the dam base and scenarios of sheet pile at the dam toe or heel, Value CENT $_{\text {is }}$ the result of the variable for the scenarios of sheet pile at the centre of the dam base and Value $E_{E X T}$ is the value of the variable for the scenarios of the sheet pile at the dam heel or toe.

Values of the comparison of groundwater flow for isotropic soils are, therefore:

- $\% Q_{I . S . C-I . S . H}=6.10 \%$.

- $\% Q_{I . S . C-I . S . T}=6.10 \%$.

In anisotropic scenarios, these values would be:

- $\% Q_{\text {A.S.C-A.S.H }}=1.97 \%$.

- $\% Q_{\text {A.S.C-A.S.T }}=1.97 \%$.

The comparison percentages for the uplift force in isotropic scenarios are:

- $\quad \% F_{\text {I.S.C-I.S.H }}=37.07 \%$.

- $\quad \% F_{\text {I.S.C-I.S.T }}=-37.05 \%$.

In the same way, for anisotropic soils:

- $\quad \% F_{\text {A.S.C-A.S.H }}=67.87 \%$.

- $\quad \% F_{\text {A.S.C-A.S.T }}=-67.87 \%$.

The application point in isotropic soils has the following comparison values:

- $\% C_{\text {I.S.C-I.S.H }}=-19.02 \%$.

- $\quad \% C_{\text {I.S.C-I.S.T }}=-38.08 \%$.

Finally, the percentages for anisotropic soils are:

- $\% C_{\text {A.S.C-A.S.H }}=-30.85 \%$.

- $\quad \% C_{\text {A.S.C-A.S.T }}=-68.44 \%$.

It is visible that the groundwater flow rate is the same when the sheet pile is located either at the heel or the toe, and it is lower than the rate generated if the pile is located at the centre of the dam base.

We can observe again that the uplift forces for scenarios of sheet pile located at the heel and the toe are symmetrical with respect to the case of sheet pile at the centre of the dam base. The difference between values is larger as the anisotropy degree is increased.

Furthermore, the lowest value of the application point seems to occur if sheet pile is located at centre of the dam base (the point is closer to the heel), while the highest value is obtained if it is placed at the dam toe (it moves towards the toe). 


\section{Conclusions}

Considering anisotropy in scenarios of flow under dams becomes important when the studied variables are those employed for safety analysis: groundwater flow, uplift force generated by pore pressure and its application point. The importance of this consideration increases if placing a sheet pile under the dam.

Simulations of different scenarios have been carried out, changing the position of the sheet pile and considering anisotropy or not. Studying the more relevant configurations, some conclusions can be reached. For scenarios of a sheet pile located at the centre of the dam base, the uplift force presents the same value as for the configuration without a sheet pile $(500 \mathrm{kN} / \mathrm{m})$, and it is not affected by anisotropy. In addition, the flow rate is reduced when a sheet pile is employed, being this reduction higher if it is placed at the dam heel or toe. For the geometrical and hydrogeological characteristics displayed in this paper, in the isotropic cases, the reduction of flow rate is of $16 \%$ if the sheet pile is at the centre of the dam base and $20 \%$ if it is placed in one of the edges. Nevertheless in anisotropic scenarios, the reductions for this variable are $37 \%$ and $38 \%$ respectively.

Finally, although building the sheet pile at the dam toe leads to a reduction of the flow rate, it also means that the uplift force is increased if compared to the results without a sheet pile. For our examples, in isotropic scenarios the uplift force is increased $37 \%$ and its application point $21 \%$, and in anisotropic soils these percentages are $68 \%$ and $27 \%$ respectively. It means that a higher load is applied to the structure, a higher load if anisotropy degrees higher than 1 are considered. These numerical solutions can be employed in the geotechnical safety analysis of a dam.

\section{Acknowledgements}

The authors would like to thank the SéNeCa Foundation for the support given to this research and for the scholarships awarded to one of the authors.

\section{References}

[1] SPANCOLD. Instrucción para el Proyecto, Construcción y Explotación de Grandes Presas. 1967.

[2] CEN. Eurocode-7 Geotechnical design - Part 1: General rules. 2004.

[3] A. A. Ahmed and A. M. Elleboudy (2010). "Effect of sheet pile configuration on seepage beneath hydraulic structures", in International Conference Scour and Erosion (ISCE-5), San Francisco, CA, 2010, pp. 511-518.

[4] M. E. Harr. Groundwater and seepage. Courier Corporation. 2012

[5] M. Muskat. The flow of homogeneous fluids through porous media. McGraw-Hill Book Company. 1937.

[6] E. Martínez-Moreno, G. Garcia-Ros, G. and Alhama, I. "A different approach to the network method: continuity equation in flow through porous media under retaining structures". Engineering Computations, vol. 37, no. 9, pp. 32693291. 2020. https://doi.org/10.1108/EC-10-2019-0493.

[7] G. García-Ros, I. Alhama and J. L. Morales, J. L. "Numerical simulation of nonlinear consolidation problems by models based on the network method". Applied Mathematical Modelling, vol. 69, pp. 604-620. 2019 https://doi.org/10.1016/j.apm.2019.01.003

[8] A. S. Meca, F. A. López and V. G. Fernández. "Density-driven flow and solute transport problems. A 2-D numerical model based on the network simulation method". Computer physics communications, vol. 177, no. 9, pp. 720-728. 2007. https://doi.org/10.1016/j.cpc.2007.06.008

[9] M. Cánovas, I. Alhama, E. Trigueros and F. Alhama, F. "Numerical simulation of Nusselt-Rayleigh correlation in Bènard cells. A solution based on the network simulation method". International Journal of Numerical Methods for Heat \& Fluid Flow, vol. 25, no. 5,pp, 986-997. 2015. https://doi.org/10.1108/HFF-09-2014-0282

[10] Ngspice. (2016). Open Source mixed mode, mixed level circuit simulator (based on Berkeley’s Spice3f5). [Online]. Available: http://ngspice.sourceforge.net/ 